\title{
Human Non-persons, Feticide, and the Erosion of Dignity
}

\author{
Daryl Pullman
}

Received: 24 November 2009/Accepted: 4 August 2010/Published online: 8 October 2010

(C) The Author(s) 2010. This article is published with open access at Springerlink.com

\begin{abstract}
Feticide, the practice of terminating the life of an otherwise viable fetus in utero, has become an increasingly common practice in obstetric centres around the globe, a concomitant of antenatal screening technologies. This paper examines this expanding practice in light of the concept of human dignity. Although it is assumed from the outset that even viable human fetuses are not persons and as such do not enjoy full membership in the moral community, it is argued that the fact that these are nevertheless human fetuses affords them prima facie moral status. Thus even those who accept a liberal position with regard to therapeutic abortion, should be concerned about these more recent developments. Indeed, how we treat viable human fetuses has implications for our prospective treatment of other human non-persons and could undermine the common human dignity we all share.
\end{abstract}

Keywords Human dignity · Feticide · Therapeutic abortion $\cdot$ Antenatal screening $\cdot$ Personhood $\cdot$ Moral agency

D. Pullman $(\bowtie)$

Faculty of Medicine, Memorial University,

St. John's, NL A1B 3V6, Canada

e-mail: dpullman@mun.ca
The life of a single human organism demands respect and protection, then, no matter in what form or shape, because of the complex creative investment it represents and because of our wonder at the divine or evolutionary processes that produce new lives from old ones, at the processes of nation and community and language through which a human being will come to absorb and continue hundreds of generations of cultures and forms of life and value, and, finally, when mental life has begun and flourishes, at the process of internal personal creation and judgment by which a person will make and remake himself, a mysterious, inescapable process in which we each participate, and which is therefore the most powerful and inevitable source of empathy and communion we have with every other creature who faces the same frightening challenge. The horror we feel in the willful destruction of a human life reflects our shared inarticulate sense of the intrinsic importance of each of these dimensions of investment.

Ronald Dworkin $(1993,84)$

Science and technology drive clinical practice. Given the rapidity of these advances, at times new practices evolve without the benefit of close public scrutiny. The advent of diagnostic imaging and genetic testing, for example, spawned the entirely new field of genetic counseling as these technologies made it possible to predict the risk of disease or 
disability of the developing fetus. Prospective parents were thus presented with the option of terminating a previously wanted pregnancy. At times, however, the process required to confirm a suspected diagnosis results in a decision to terminate later in the gestational process. Not only does this present additional obstetrical challenges, but it raises the possibility of a live birth. In order to forestall this latter eventuality, feticide has become an increasingly common practice in obstetrical centers around the globe, a concomitant of previously accepted prenatal screening practices (Bijma et al. 2007; Graham et al. 2008; 2009; Dommergues et al. 2003; Chen et al. 2009).

For more than a decade one particularly controversial means of feticide has been the subject of intense debate in the United States. That practice, known colloquially as "partial birth abortion" and described somewhat less emotively in medical parlance as "dilation and extraction" (D\&X), has reinvigorated the therapeutic abortion debate in that country (Rovner 2006). The Bush administration finally pushed through the Partial Birth Abortion Ban Act in 2003 to make D\&X illegal. That legislation subsequently withstood a constitutional challenge when it was upheld by the US Supreme Court in 2007. Critics of both the initial legislation and the Supreme Court's decision have objected to the "overtly political discourse" that invokes "respect for the dignity of human life" and which claims that the act of abortion has the power to "devalue" human life (Gostin 2007, 1563).

Characterizing the concept of human dignity as a political notion rather than as a fundamental moral concept has become somewhat commonplace in recent years. Some have dismissed human dignity entirely as a morally vacuous notion (Macklin 2003). Others complain that the term has been co-opted by special interest groups to advance their own agendas. Beyleveld and Brownsword (2001) have been particularly articulate in this regard, referring pejoratively to the "dignitarian alliance" that invokes dignity as a kind of moral trump card that brings all discussion on sensitive ethical matters to an end (Brownsword 2003, 425). Be that as it may, the concept of human dignity continues to play a foundational role in many of our most critical international declarations, conventions, and consensus statements (Universal Declaration of Human Rights 1948; President's Council 2002). Thus it behooves us to think carefully about the normative force this concept might continue to exert.
The purpose of this paper is to examine the practice of feticide in light of the concept of human dignity. Although it isn't possible to deal with the question of feticide without touching on some of the broader ethical concerns associated with therapeutic abortion in general, the ethics of selective termination, and the concerns raised by advocates for the disabled (Wasserman et al. 2005), our focus here will be more narrowly on feticide, the intentional killing of otherwise viable fetuses. The discussion to follow begins by reflecting upon the broader moral and legal frameworks in which the practice of feticide has evolved. Most countries that permit (or do not restrict) the use of feticide are signatories to or otherwise recognize various international conventions that uphold the inherent dignity of all members of the human family, and predicate a regime of rights based on this foundational concept. While virtually all countries provide some level of legal protection to the newborn infant, most are ambiguous with regard to the moral and legal status of the viable fetus. It is this ambiguity that permits the termination of otherwise viable fetuses on the one hand, but which often results in aggressive intervention with premature newborns on the other (Gross 1999, 2002).

Historically, much of the debate regarding therapeutic abortion has revolved around the question of fetal personhood (Gross 1999). For present purposes we will bracket that particularly intractable aspect of the debate in order to focus on the concept of dignity. For the sake of argument we will suppose that fetuses are not persons in any robust sense at any stage of gestation (Warren 1973). However, while not persons per se they are nevertheless human fetuses. Part of our task is to determine what if any status human nonpersons might have within a moral community that claims to recognize fundamental human worth, and what if any protections otherwise viable human fetuses might thus be afforded under the banner of human dignity. The aim is to develop a moral perspective that invokes a notion of human dignity that captures broad moral intuitions, without succumbing to political sloganeering (Caulfield and Brownsword 2006, 76).

The argument presented here is intended to advance our understanding of human dignity while casting some light on the question of feticide in particular and our treatment of human non-persons more generally. The paper unfolds in three stages. 
First, I outline some of the changes in pre-natal screening and related genetic technologies that have led to the expanding practice of late terminations of otherwise viable pregnancies in many jurisdictions around the globe. Second, I examine some competing conceptions of human dignity and argue for a preferred model that overcomes some of the shortcomings of the alternative view while situating the question of feticide within a broad moral framework. The preferred understanding of human dignity is then invoked in the later part of the paper to inform our understanding of the ethics of feticide.

\section{Medicine, Morality and the Law}

By the 1990s the obstetric ultrasound was well entrenched as a standard of care, supplemented increasingly by genetic services and biochemical screening. As more anomalous fetuses were identified, later-term abortions became more frequent. It is easy to lose sight of how the emergence of these clinical practices essentially changed the terms of reference of the abortion debate.

Before the wide availability of antenatal screening technologies, the abortion issue was framed narrowly in terms of individual autonomy and a woman's right to choose. The focus was squarely on the woman and only incidentally on the fetus. It didn't matter whether she was pregnant due to failed contraception, carelessness, or had simply changed her mind; the fact that she did not want a baby (that is, any baby) at this point in her life was sufficient to justify her decision to terminate the pregnancy. Inasmuch as a woman is generally aware that she is pregnant relatively early in the gestation period, the process of termination is fairly straightforward and is usually carried out well before the point of viability. Indeed the vast majority of terminations fall squarely into this category. Hence most jurisdictions eventually recognized a woman's autonomy rights in this regard, and early term abortion services became widely available. ${ }^{1}$

\footnotetext{
${ }^{1}$ While the woman's right to choose was central to most of the national public debates, not all jurisdictions emphasize autonomy rights to the same degree in their legislative responses. In England, for example, abortion law is not concerned primarily about the woman's autonomy and is not rights-based, although this has been a point of some controversy (Scott 203).
}

With the advent of prenatal screening the terms of reference of the abortion debate changed. Now the decision to abort was often made not by a woman who did not want to be pregnant, but by one who had decided to become pregnant and who could have terminated her pregnancy earlier. Her late decision to terminate was based on information gained through prenatal testing. Given the woman's initial desire to have $a$ baby, but her later decision not to have this baby, the focus now shifts to the fetus she has decided to abort. When this shift occurs the question is no longer simply about a woman's reproductive freedom, but rather about the determination of legitimate grounds for terminating the lives of particular, often viable, fetuses. No longer can this be characterized simply as an individual woman's autonomous right to choose, or as a medical matter to be decided between a woman and her physician. As will be argued presently, what society allows or accepts in this regard has implications for the dignity in which we all have a stake.

To date, the most thorough comparative analysis of international practices with regard to feticide has been conducted by Michael Gross (1999, 2002). Writing in 1999 Gross observed: “the general issue of a woman's right to an abortion, at least in Western democracies, is largely settled. In its place, the question of late-term abortions begins to assume a prominence only recently attributed to abortion itself" (1999, 449). Gross is only partially right. While the question of abortion does not figure as prominently in public moral discourse, the issue of feticide has not replaced it as a general public concern. Instead, 10 years on from when Gross made his initial observations the practice of feticide is expanding without rekindling the broad debate he had anticipated. Several distinct but related reasons can be adduced for this, including moral conflation, medical hegemony, and moral particularism.

Moral conflation involves a failure to distinguish distinct moral issues, thus confusing one with the other. Once Western democracies had more or less settled the question of abortion in favor of the woman's right to choose, the question of the moral status of the fetus faded into the background. Although various courts have at times acknowledged that not every regulation of termination of pregnancy constitutes an interference with private life (Wicks et al. 2004), and that the fetus has interests that should 
be recognized (Kent 2005, 166; Gross 2002, 204), legislatures and the courts have either found it difficult or have been reluctant to regulate late terminations. As long as the courts recognize a woman's right to abortion, but fail to account for the manner in which prenatal screening has changed the terms of reference of the debate, the question of the moral status of the late-term fetus will continue to be conflated with that of a woman's reproductive liberty. This is borne out, for example, by the expanding case law on "wrongful birth" in which the right to abort $a$ fetus has been extended to include the right to access information in order to determine whether to abort this fetus (Scott 2003).

When legislatures and the courts fail to recognize the interests of the late term fetus, medical professionals are left to their own devices to sort out an appropriate standard of care. As the practice of feticide expanded throughout the 1990s, medical practitioners struggled to come to grips with whether they served one patient or two when caring for a pregnant woman. Some focused almost exclusively on the woman as patient and advocated for the use of feticide as a means to avoid potential legal perils associated with a live birth, to reduce medical risks, and to limit psychological harm (Fletcher et al. 1992). Others argued that the fetus is a patient from the point of viability and advocated for severe limitations on late term abortions (Chervenak et al. 1995).

Medical hegemony refers both to the manner in which evolving standards of practice can mask or circumvent the moral issues at hand, and how medicine can in turn assume that the issues are primarily clinical. Diagnostic imaging and prenatal screening technologies are now the standard of care in medicine. Even at this late date, however, many patients fail to appreciate the moral implications that the use of these technologies can entail. One recent European study observes: "Most women consider ultrasound examinations as an integral part of antenatal care. However, frequently, women lack information about the purpose of ultrasound examinations and its technical limitations. As a result, women are often unprepared for adverse findings" (Bijma et al. 2007). Another study confirms that clinical technique has effectively supplanted moral debate: "Within the medical literature, attention tends to focus on the progressive development of technique by which feticide can be achieved. This technical literature says little about the complexities of feticide within its social context. The term feticide appears to be used as if it were unproblematic, a neutral term that describes a clinical procedure" (Graham et al. 2008, 291).

Feticide is now firmly entrenched as a standard of medical practice. Thus the International Federation of Gynecology and Obstetrics recommends that "Termination of pregnancy following prenatal diagnosis after 22 weeks must be preceded by a feticide" (FIGO 2008, 98). In jurisdictions where the practice is somewhat restricted, as, for example, in parts of Australia and under the recent ban on partial birth abortion in the US, commentators complain that such restrictions limit patient access to procedures that are recognized in the profession, while curtailing practitioner's freedom to exercise clinical judgment (De Crepigny and Savulescu 2008; Gostin 2007).

Moral conflation and medical hegemony describe two phenomena that have facilitated the expansion of feticide in recent years. However, while the use of feticide has expanded generally, the details of this expansion in terms of the extent to which it is used, the means by which it is regulated, if at all, and so forth, have varied across jurisdictions. Moral particularism describes the manner in which the practice of feticide has unfolded within specific national and cultural contexts, and the idiosyncratic policies and practices that have sprung up around it. Here I draw on Gross's (1999, 2002) excellent work to describe something of this phenomenon.

Gross is interested in the practice of feticide and selective non-treatment of newborns (neonanticide). $\mathrm{He}$ is puzzled by the fact that nations that share similar underlying political cultures have not adopted similar policies. He notes: "The same moderately malformed 25 week old fetus might be aborted in Israel, delivered but not necessarily resuscitated in Denmark, resuscitated but not always treated aggressively in the UK, and treated aggressively in the US" (2002, 203).

On the one hand the development of disparate policies is understandable. Although Western democracies share similar political cultures these similarities exist at only the most general level. Each nation has its own unique history, geography, and economy, is influenced by different religious and cultural norms, and has particular means by which to allocate health care resources. Hence the question of abortion in general and feticide in particular has played out within each jurisdiction's particular milieu. However, 
while this may serve as an explanation for how particular policies can vary, it is not a justification for vast differences when the practice in question involves the termination of an otherwise viable human life. Thus Gross wonders whether nations with similar political cultures shouldn't adopt similar policies on such a fundamental issue: "Either these countries do not share the same norms, or the norms are sufficiently elastic to permit wildly diverse policy, or some policy is just plain wrong" (2002, 204).

Although Gross does not distinguish between values and norms, that distinction is important here. In fact, it would be more accurate to say that in spite of different norms Western polities share some fundamental values that have been captured historically in the notion of dignity. This last serves as a fitting segue into a discussion of human dignity and how this fundamental moral notion bears on the practice of feticide. Anticipating what lies ahead, we will respond to Gross's tripartite disjunction as follows: (1) irrespective of the particularities of local custom and practice, Western democracies do indeed share some basic fundamental values which are captured in the notion of human dignity; (2) while the notion of dignity is sufficiently elastic to permit some variation in policy, it is not so elastic as to permit wildly diverse policies on the issue of feticide; and (3) some current policy with regard to feticide is indeed just plain wrong.

\section{Understanding Human Dignity}

Forty years ago the late Herbert Spiegelberg contributed to a volume of essays on the subject of human dignity. He observed (1970, 62): "Human dignity seems to be one of the few common values in our world of philosophical pluralism ... The main hurdle at the moment is that there is not enough clarity about the meaning of human dignity. To provide it is the responsibility of all philosophers." Leon Kass, writing more than three decades later, echoes Spiegelberg's general observation: "Human dignity is ... a useful notion, perhaps even the right one ... Yet if it is to be more than an empty slogan, we need to articulate its meaning" (2002, 14-15).

Over the past two decades I have made several contributions to the dignity literature in an attempt to articulate its meaning. Some of that work is more theoretical in nature (Pullman 2002a, b, 2006), while other pieces address particular health ethics issues (Pullman 1996, 1999, 2004a). While I will not rehearse the details of those various discussions here, it will be necessary to provide a general outline of the manner in which I articulate my understanding of dignity in order to inform our discussion of feticide. Before doing so, however, I want to outline an alternate understanding of human dignity promulgated by Derek Beyleveld and Roger Brownsword (2001). I focus on their work for three reasons: (1) Beyleveld and Brownsword provide the most systematic and comprehensive explication of the subject to date; (2) my own explication of human dignity runs contrary to their preferred interpretation at several points, particularly with regard to human nonpersons; and, finally (3) the notion of dignity Beyleveld and Brownsword prefer provides questionable direction on the issue of feticide.

Beyleveld and Brownsword distinguish two rival conceptions of human dignity, which they term dignity as empowerment and dignity as constraint (2001, 9ff). Dignity as empowerment is their preferred view, but they worry that dignity as constraint is making inroads in contemporary bioethics and biolaw. In their view dignity as constraint is a recent conception instantiated in broad international statements such as the Convention on Human Rights and Biomedicine, and the Universal Declaration of the Human Genome and Human Rights. The hallmark of this notion is that it invokes dignity to constrain free choice. Dignity as constraint is invoked, for example, to deny parents the opportunity to sex select their children or to use genetic technologies to create "designer children," to prohibit agents from participating in commerce of the human body, from cloning human cells, to curtail active euthanasia, and so forth $(2001,4)$. On this view human dignity constrains by propounding some conception of a collective good that represents society's vision of the kind of community it wants to be, and by suggesting it is as wrong to compromise one's own dignity as it is to compromise the dignity of others $(2001,11)$.

Beyleveld and Brownsword are particularly concerned about the manner in which recent human rights instruments foreground human dignity and then use it to limit free choice. They maintain that earlier instruments, such as those developed immediately after the Second World War, did not afford human 
dignity such a substantive role. Instead human dignity remained in the background to serve as a basis for equal respect and to ground human rights (2001, 12-13). Human rights, in their preferred view, are enjoyed by human agents who alone have the capacity to act upon or waive those rights $(2001,118)$. However, more recent instruments such as the European Convention on Human Rights have expanded the role of dignity and have extended its reach to cover not just full human agents, but human non-agents and partial agents such as embryos and fetuses as well.

Dignity as constraint thus runs headlong into liberal notions of autonomy that Beyleveld and Brownsword are wont to defend. "[I]f embryonic and foetal life is protected under the cover of respect for human dignity (in its new extended sense)," they note, "then the autonomous choices of researchers (for example, to create, test, manipulate, and store embryos) and of women (to terminate pregnancies) must be measured for their legitimacy against not only the general regime of human rights, but also against the special dignity-based regime protecting such early human life" (2001, 32-33). Now while some may not be overly concerned that the autonomous choices of researchers and the decisions of women with regard to the disposition of otherwise viable fetuses should be open to some level of public scrutiny, Beyleveld and Brownsword find this troubling. Dignity as constraint, they complain, curtails individual freedom by propounding a subjective and nebulous conception of a collective good.

Dignity as empowerment is, in their view, the more traditional conception that serves as the basis for the regime of individual human rights that developed in the post-World War Two era. On this reading intrinsic human dignity plays something of a formal role in that it serves as "the background justification for the recognition of human rights and as the source of the fundamental freedoms to which all humans (qua human) are entitled" $(2001,11)$. But once dignity as empowerment establishes the basis of human rights it stands back and leaves the heavy normative work to the notions of agency and rights. Thus Beyleveld and Brownsword devote most of their effort to an explication of the notion of agency: "If (as we hold) the essence of the dignity of agents resides in their capacity to choose, to set their own ends, then we respect that dignity by creating the conditions and opportunities for choice and recognizing agents as sources of informed choice" $(2001,5)$.

The notion of agency and generic rights Beyleveld and Brownsword develop draws heavily on the work of Alan Gewirth $(1978,1982)$. It is neither possible nor necessary to describe Gewirth's contribution in any detail here. For our current purposes, however, it is important to note how their Gewirthian rendering results in a complete metamorphosis of the notion of human dignity, effectively turning it on its head. That is, although they begin by recognizing the intrinsic dignity of humanity as the basis of human rights (2001, 11), by the time they have constructed their Gewirthian notion of agency and tied it to a conception of generic rights, dignity becomes contingent on agency: "In Gewirthian theory beings have dignity if and only if they are agents. All agents are, therefore, equal in their dignity and possess equal generic rights” $(2001,148)$. Elsewhere they state: “ ... we are committed to the view that agency is the ground of human dignity" (2001, 157).

Now all of this has implications for the moral standing of human non-persons/non-agents in general, and for how we think about feticide in particular. For if agency is the ground of human dignity, and if having the generic capacities of agency is necessary for having generic rights, then partial agents or nonagents cannot have any rights at all: "Having the generic capacities of agency to the degree needed to be an agent is not only necessary (and sufficient) to have the generic rights in full ... it is necessary to have any generic rights at all. This is because, as derived, the generic rights are rights under the will conception of rights ... Thus, partial agents cannot have any generic rights" (2001, 118 their emphasis).

Elsewhere Beyleveld and Brownsword acknowledge that human rights instruments do occasionally grant rights to "very young children, foetuses, the dead, and members of the human biological species," but they consider such extensions to be in some sense derivative and secondary to the status of full agents $(2001,81)$. Indeed, given their insistence that full agency is both necessary for rights and serves as the ground of human dignity, it seems that such secondary and derivative extensions of rights to non-agents (such as fetuses) would effectively weaken the notion of dignity tied to full agency. Under dignity as empowerment then a women as full agent has dignity, while her fetus as a non-agent has none. To extend some derivative or 
secondary notion of agency to the fetus by invoking some notion of dignity then, would be to invoke "dignity as constraint" in order to curtail "dignity as empowerment." Thus any attempt to limit the free choices of women to do as they please vis-à-vis feticide, would, on their view, be an offence to human dignity.

In order to demonstrate the inherent weaknesses of Beyleveld's and Brownsword's conception of dignity, and the concomitant notions of agency and rights they espouse, I turn now to sketch an alternative interpretation of dignity which, as noted previously, I have developed in various contexts over the past number of years. Like Beyleveld and Brownsword I begin by noting that there are different conceptions of human dignity extant that are invoked variously in moral discourse. I recognize as well that historically the notion of dignity conveys the idea that human beings are intrinsically valuable and are thus worthy of respect. Beyond these basic observations, however, my understanding of human dignity diverges significantly from their account. In particular, as it relates to the issue of feticide, my understanding extends the notion of dignity to include human fetuses, and it includes them not only secondarily or derivatively but simply by virtue of the fact that they are, after all "human" fetuses. On this view responding to the inherent dignity of fetuses and other human nonpersons does not weaken the dignity claims that full persons (or agents) enjoy; rather it serves to express, enhance and preserve that dignity. However, to recognize that fetuses have dignity does not entail that they are entitled to the full measure of rights afforded full human agents, but only that insofar as they are human they deserve moral consideration. How is this so?

My account begins by distinguishing a universal, basic, ascriptive conception of human dignity, from various particular, personal, and expressivist accounts. The former notion, which I refer to simply as "basic dignity," ascribes worth to human beings simply on the basis of being human. When used in this ascriptive sense we mean to convey the idea that all human entities have basic moral worth irrespective of any contingent historical, traditional, or cultural circumstance. One does nothing to earn basic dignity and one can do nothing to lose it. Just being human invests one with this basic moral worth irrespective of rank or station. It is this conception that is in view, for example, when we refer to the inviolability of human dignity, to the intrinsic moral worth of all humanity, and when we speak of inalienable human rights founded upon and expressive of dignity. The essence of this conception is not that people have a right to be treated with dignity, but rather that people have rights because they have dignity. Apropos of the current discussion, and pace Beyleveld and Brownsword, basic dignity is not contingent on agency. Any human entity enjoys a prima facie claim to moral consideration simply by virtue of being human. ${ }^{2}$

This basic, universal notion is distinct from various particular expressions. I collect the latter together under the rubric "personal dignity." Here "personal" should not be confused with "individual." Rather the intent is to capture the fact that the self is a socially constructed entity. Personal dignity is thus tied to notions of self-respect and self-esteem, and is intimately related to the complex social and psychological processes involved in self formation and self expression. As such, perspectives on personal dignity will vary with historical, cultural and traditional experiences and values, as individuals and communities engage in the ongoing process of defining who they are and what they want to become. While some of these journeys of self formation and self expression might tend toward more individualistic conceptions, others may reflect broader community inputs and a broader corporate sense of self. Thus it is personal dignity that is in view when we say that people have a right to be treated with dignity, meaning we should respect who they are and who they are striving to become as persons.

Given this understanding it is clear that there will always be a variety of expressions of personal dignity extant, and at times some expressions might conflict.

\footnotetext{
${ }^{2} \mathrm{I}$ am aware that this understanding of dignity is subject to a charge of speciesism, that is, that it privileges the human species over other species. I acknowledge this charge but remain unconvinced of its merit. In general my response revolves around the notion of agency, and the distinction between moral agents and moral subjects. Human beings alone are capable of moral agency (i.e. incurring duties and obligations), although human non-persons and non-human animals are moral subjects (i.e. are deserving of moral consideration). Thus, rather than serving to ground moral rights, as Beyleveld and Brownsword claim, moral agency is the basis of moral obligation. So while humans have moral obligations to other species, we can expect no such consideration from them. For a somewhat fuller response see Pullman $2004 b$.
} 
How such conflicts should be resolved is a longstanding problem in social political philosophy and we cannot engage further in that discussion here. For present purposes we need note only that both "dignity as constraint" and "dignity as empowerment," as described by Beyleveld and Brownsword, can, on this reading, be characterized as alternative understandings of "personal dignity." That is, each conception advances a particular understanding of what it is to live a dignified existence, the former maintaining a self understanding that draws upon wider communitarian values, and the latter maintaining that individualistic conceptions of personal dignity should hold sway.

As important as the notion of personal dignity is to our understanding of the variety of ways in which dignity is expressed both in community values and individual choices, it is basic dignity that grounds these various expressivist accounts. That is, the idea that humanity has intrinsic worth has functioned historically as a kind of logical primitive in moral discourse. Kant captures this general notion most famously in the Categorical Imperative, and Habermas draws upon it as well when he alludes to "a prior ethical selfunderstanding of the species, which is shared by all moral persons"(2003, 40). Samuel Fleischaker (1994, 17) sums it up this way: "It is not merely out of a desire to spread our own way of life that we demand universal acknowledgment of a certain fundamental dignity in all human beings. We cannot avoid believing that those who do not recognize human dignity are wrong about something; that they have failed to recognize something about the very nature of morality." Indeed it is this notion that Beyleveld and Brownsword have in mind when they speak of intrinsic dignity "that acts as the background justification for the recognition of human rights and as the source of the fundamental freedoms to which all humans (qua human) are entitled" $(2001,11)$.

Basic dignity and personal dignity are complementary notions. Both are essential to a proper understanding of the full concept of dignity. How we characterize the relationship between the two conceptions is critical both to a proper appreciation for how the notion of human dignity functions in moral discourse in general, and for how appeals to dignity impact on particular ethical problems. It is also important to an understanding of how human nonpersons who are not self-consciously aware and thus cannot have a sense of self or a notion of personal dignity (individual, communal or otherwise), might nevertheless deserve moral consideration under the auspices of basic dignity.

Elsewhere I have characterized the dynamic relationship between basic and personal dignity in terms of ethical and aesthetical values (Pullman 2002a), and have mapped it to the universalism/particularism distinction (Pullman 2002b). For our purposes here we can think of the relationship in terms of form and content. Basic dignity thus acts as a formal meaning constraint on moral discourse in the broad sense, and particularist expressions of what it is to have a meaningful and dignified existence provide the content. Again, I have developed the idea that basic dignity functions as a meaning constraint on moral discourse elsewhere (Pullman 2004a) and will not reiterate that detail here. The key point is that moral language presupposes a notion of basic human dignity that requires that human beings are granted prima facie moral standing. As a formal epistemic constraint basic dignity functions to set the epistemic boundary on what passes as meaningful moral discourse. Thus it functions primarily as an epistemic constraint, and only incidentally (although necessarily) as a moral constraint. The content of the full conception of dignity is provided then by particularist understandings of what it means to live a dignified life. Both conceptions are necessary to a full understanding of human dignity. To paraphrase Kant's famous aphorism: basic dignity without personal dignity is empty; personal dignity without basic dignity is blind.

\section{Feticide and the Erosion of Dignity}

We return finally to the issue of feticide, and how the understanding of dignity presented here might inform that discussion. To begin, I want to return to the notion of dignity as empowerment as advanced by Beyleveld and Brownsword. Earlier it was noted that given their explication, fetuses lack agency and would ipso facto lack dignity. Thus fetuses, as such, have no claim to the generic rights. Dignity as empowerment then says nothing about the issue of feticide other than that each woman as a full agent is free to choose feticide or not depending on her own view of the good life. Fetuses as such are outside of the moral community. This, I take it, is the plain reading of their 
position. It is interesting then that these authors return to the issue of the moral status of embryos and fetuses, and attempt to open a door by which to grant them moral status after all. In order to do so they invoke "precautionary reasoning" that "requires agents to recognize duties to the unborn in proportion to the degree to which the unborn display characteristics associated with the ability to display agency" (2001, 157-8).

Now on the one hand it is not surprising that Beyleveld and Brownsword want to find a way to shoehorn human non-persons/non-agents back into the moral community. Any conception of morality that denies any measure of moral standing whatsoever to human non-agents would border on moral nonsense. As such it would violate the epistemic constraint supplied by the notion of basic dignity outlined above. Thus Beyleveld and Brownsword are to be commended on this score. On the other hand, their attempt to argue that embryos and fetuses might display characteristics associated with agency, and hence should be afforded moral consideration on this basis, is weak at best; it flies in the face of the Gewirthian notions of agency and generic rights they expound so forcefully elsewhere. So while we can agree that "it is on account of considerations of dignity that duties to the embryo arise," and that "not to take account of these considerations is to act in violation of human dignity," (2001, 158) their explication of the nature of dignity tied to agency simply doesn't support this application.

The problem with dignity as empowerment tied to a strong notion of agency is that it results in a very restricted conception of dignity. Many human nonagents/non-persons that most would agree should have some measure of moral standing are excluded. While opinions may vary with regard to the status of embryos and early stage fetuses, moral intuitions begin to converge around viable fetuses, newborns, very young children, the mentally challenged, those suffering from advanced dementia, and so forth. However, all of these fall beyond the pale of morality and dignity tied to agency in the strict Gewirthian sense advanced by Beyleveld and Brownsword. This is because "the generic rights are rights under the will conception of rights ... Thus, partial agents cannot have any generic rights" $(2001,118)$.

On the alternate view of basic dignity as epistemic constraint, human fetuses have prima facie moral standing simply by virtue of being human. The same holds for other human non-persons/non-agents including human gametes, human embryos, those who suffer from advanced dementia and have thus lost the capacity for agency, and so forth. Here the dignity possessed by these human entities is based on their biological connection to the rest of the human species. However, pace Beyleveld and Brownsword (2001, 166), it does not follow that every human biological specimen must thus be afforded equal moral worth. As an epistemic constraint basic dignity requires only that human entities be given prima facie moral consideration. How we dispose over them is another matter. For the time being we need acknowledge only that the fact that these are human entities is not inconsequential.

While dignity as empowerment results in a very restricted conception of dignity, basic dignity as epistemic constraint could be charged with suffering from the opposite problem. That is, by granting some measure of moral status to all human specimens we risk diluting the notion of dignity completely. Here again, however, we must reiterate that basic dignity functions primarily as a meaning constraint that shapes the nature of moral discourse in the broad sense. Personal dignity then provides the content through the individual and corporate projects in which we engage and by which we come to understand and express the kinds of people we are and want to become. Basic dignity constrains this self-understanding by ensuring that we consider carefully how our treatment of any human entity affects the broad moral discourse that we share as a moral community. Thus moral discourse constrained by basic dignity acknowledges that not every human entity is worthy of full moral consideration; human tissues are clearly not equivalent to human persons. Nevertheless, the fact that it is human tissue as opposed to non-human animal or plant tissue, for example, gives it prima facie moral significance.

On occasion I've employed a balloon analogy to illustrate how basic dignity serves as an epistemic constraint on moral discourse, and to capture the dynamic relationship between basic and personal dignity (Pullman 2002b, 2004a) On this analogy the skin of the balloon represents basic dignity, while the contents represent various particularist expressions. Inasmuch as the skin of a balloon is elastic, this epistemic constraint can stretch to accommodate a variety of particularist understandings of what it 
means to live a dignified life. As such it can accommodate conceptions of the human good that use human tissues for experimentation, permit the termination of early term fetuses, and perhaps even consider circumstances in which beneficent euthanasia of otherwise viable human beings might be permissible. However, each of these practices exerts some degree of pressure on the basic epistemic constraint, stretching it in the process. As such we must consider carefully any practices that might stretch or erode that basic constraint to the point that we lose that common understanding of morality tied to a notion of dignity that has in one way or another shaped much of our moral understanding of the kinds of people we are and can be.

We return now to Gross's (2002) consternation as to why countries that share similar political cultures can diverge so much in terms of policy and practice on the issue of feticide. He speculates that either these cultures do not share similar values/norms after all, or that the basic values they do share are sufficiently elastic to accommodate wide variation in practice, or that some policies are just wrong. In light of the full concept of human dignity outlined here, we can now respond as follows. All moral communities share a common value in the notion of basic human dignity that ascribes basic moral worth to all humanity. The nature of morality is such that this notion functions as an epistemic constraint on all moral discourse. At the same time the notion of basic dignity is sufficiently elastic to allow for some variation in policy and practice between particular moral communities, and with regard to the treatment of particular human entities within those communities. This policy and practice manifests itself in the variety of community and individual self-understandings and expressions of personal dignity that exist in all liberal democratic societies. However, this elasticity is not without limits. Any community that has lost the moral vocabulary by which to restrain certain human behaviors with regard to how its members dispose over human non-persons in general, and, given our focus here, over the terminations of viable human fetuses in particular, risks drifting into moral nonsense. Put otherwise, some liberal policy with regard to the issue of feticide is just wrong. Indeed, one practical policy outcome of the moral arguments advanced here would be that viable fetuses (irrespective of potential anomalies) should enjoy the same legal protections as newborn infants.
This discussion has not addressed the circumstances under which feticide might be permissible. Clearly risks to the mother's health must be considered, although recent literature suggests that when the door is opened to include both the physical and emotional wellbeing of the mother as determined within the context of other "medical decisions," the ability to restrict the practice of feticide is compromised significantly (Wicks et al. 2004, 287). There has been little research conducted to date on the long-term emotional effects for women who have elected late-term abortions (Graham et al. 2008; Fisher 2008). Other issues include the concerns raised by disability rights advocates and those related to the potential pain and suffering of anomalous newborns. ${ }^{3}$ All of these concerns are related, and how we respond to each has implications for how we will think about our dignity as human beings in the future.

\section{Conclusion}

This paper opens with a quotation from Ronald Dworkin that stresses the importance of thinking seriously about our treatment of all human existence. I close now with a more recent quotation from Leon Kass. He writes $(2002,197)$ :

In the 35 years since I began thinking about these matters, our society has overcome longstanding taboos and aversions to accept testtube fertilization, commercial sperm banking, surrogate motherhood, abortion on demand, exploitation of fetal tissue, creation of human embryos solely for experimentation, patenting of living human tissue, gender-change surgery, liposuction and body shops, the widespread shuttling of human parts, assisted suicide practiced by doctors, and the deliberate generation of human beings to serve as transplant donorsnot to mention massive changes in the culture regarding shame, privacy and exposure.

\footnotetext{
$\overline{3}$ The question of suffering must be considered as well, whether of potential children who might suffer from debilitating or fatal illnesses, or of potential parents who might be burdened with their care. For present purposes suffice it to say that how a moral community responds in the face of human suffering provides opportunities to express and enhance human dignity. Thus simply to eliminate potential suffering through technological means could serve to undermine human dignity (see Pullman 2002a).
} 
Each of these practices has been met with some opposition, but in the end, each has achieved a level of accommodation in contemporary society. The full conception of dignity outlined here allows for such accommodation. But it suggests, as well, that each accommodation puts additional strain on the basic epistemic notion that constrains our moral discourse. The arguments we accept in order to justify each new practice forestalls counter-arguments that might be used to constrain them. In the process the notion of dignity that anchors our recognition of fundamental human rights suffers some erosion.

The issue of feticide concerns our treatment of human non-persons. At a time when we are acquiring an increasingly fine-grained ability to predict the potential health status and perhaps even the future social status of individual fetuses, we must think carefully about the rationales we use to justify such terminations. Arguments we accept now to justify the treatment of these human non-persons will have future implications for our treatment of other human non-persons as well.

Open Access This article is distributed under the terms of the Creative Commons Attribution Noncommercial License which permits any noncommercial use, distribution, and reproduction in any medium, provided the original author(s) and source are credited.

\section{References}

Beyleveld, D., and R. Brownsword. 2001. Human dignity in bioethics and biolaw. Oxford: Oxford University Press.

Bijma, H.H., A. van der Heide, and H.I.J. Wildschut. 2007. Decision-making after ultrasound diagnosis of fetal abnormality. European Clinics in Obstetrics and Gynaecology 3: 89-95.

Brownsword, R. 2003. An interest in human dignity as the basis of genomic torts. Washburn Law Journal 42: 413-487.

Caulfield, T., and R. Brownsword. 2006. Human dignity: A guide to policy making in the biotechnology era. Nature Reviews. Genetics 7: 72-76.

Chen, C.-H., H.-C. Hsieh, H.-D. Tsai, et al. 2009. Cardiac tamponade: An alternative procedure for late feticide. Taiwanese Journal of Obstetrics and Gynecology 48: 159-162.

Chervenak, F.A., L.B. McCullough, and S. Campbell. 1995. Is third trimester abortion justified? British Journal of Obstetrics and Gynecology 102: 434-435.

De Crepigny, L.L., and J. Savulescu. 2008. Pregnant women with fetal abnormalities: The forgotten people in the abortion debate. The Medical Journal of Australia 188(2): 100-103.

Dommergues, M.F., M.G. Cahen, et al. 2003. Feticide during second- and third-trimester termination of pregnancy:
Opinions of health care professionals. Fetal Diagnosis and Therapy 18: 91-97.

Dworkin, R. 1993. Life's dominion. New York: Vintage.

FIGO (International Federation of Gynecology and Obstetrics). 2008. Committee Report: Ethical aspects concerning termination of pregnancy following prenatal diagnosis. International Journal of Gynecology and Obstetrics 102: 97-98.

Fisher, J. 2008. Termination of pregnancy for fetal abnormality: The perspective of a parent support group. Reproductive Health Matters 16(31 Supplement): 57-65.

Fleischaker, S. 1994. The ethics of culture. New York: Cornell University Press.

Fletcher, J.C., N.B. Isada, P.G. Pryde, et al. 1992. Fetal intercardiac potassium chloride injection to avoid the hopeless resuscitation of an abnormal abortus: II. Ethical issues. Obstetrics and Gynecology 80(2): 310-313.

Gewirth, A. 1978. Reason and morality. Chicago: University of Chicago Press.

Gewirth, A. 1982. Human rights. Chicago: University of Chicago Press.

Gostin, L.O. 2007. Abortion politics: Clinical freedom, trust in the judiciary, and the autonomy of women. Journal of the American Medical Association 298(13): 1562-1564.

Graham, R.H., S.C. Robson, and J.M. Rankin. 2008. Understanding feticide: An analytic review. Social Science \& Medicine 66: 289-300.

Graham, R.H., K. Mason, J. Rankin, and S.C. Robson. 2009. The role of feticide in the context of late termination of pregnancy: A qualitative study of health professionals and parents' views. Prenatal Diagnosis 29: 875-881.

Gross, M.L. 1999. Special Section: The morality of abortion. After feticide: Coping with late-term abortion in Israel, Western Europe, and the United States. Cambridge Quarterly of Healthcare Ethics 8: 449-462.

Gross, M.L. 2002. Abortion and neonaticide: Ethics, practice and policy in four nations. Bioethics 16(3): 202-230.

Habermas, J. 2003. The future of human nature. Cambridge: Polity.

Kass, L. 2002. Life, liberty and the defense of dignity. San Francisco: Encounter Books.

Kent, C.A. 2005. Medical ethics: The state of the law. LexisNexis Canada: Markham.

Macklin, R. 2003. Dignity is a useless concept. BMJ 327: 14191420.

President's Council on Bioethics. 2002. Human cloning and human dignity. New York: Public Affairs.

Pullman, D. 1996. Dying with dignity and the death of dignity. Health Law Journal 4: 197-219.

Pullman, D. 1999. The Ethics of autonomy and dignity in longterm care. Canadian Journal on Aging 18/1: 26-46.

Pullman, D. 2002a. Human dignity and the ethics and aesthetics of pain and suffering. Theoretical Medicine and Bioethics 23: 75-94.

Pullman, D. 2002b. Universalism, particularism and the ethics of dignity. Christian Bioethics 7(3): 333-358.

Pullman, D. 2004a. Death, dignity and moral nonsense. Journal of Palliative Care 20(3): 171-178.

Pullman, D. 2004b. Afterthoughts: Death, dignity, and moral nonsense. Journal of Palliative Care 20(3): 178.

Pullman, D. 2006. Human dignity, moral realism and the foundations of a universal humanism. Proceedings of Metafi- 
sica 2003. Rome: Fernando Rielo Foundation-Assumption Institute.

Rovner, J. 2006. Partial-birth abortion: Separating fact from spin. National Public Radio, Feb. 21. www.npr.org/ templates/story/story.php?storyId=5168163 (accessed October 10, 2009).

Scott, R. 2003. Prenatal screening, autonomy and reasons: The relationship between the law of abortion and wrongful birth. Medical Law Review 11: 265-325.

Spiegelberg, H. 1970. Human dignity: A challenge to contemporary philosophy. In Human dignity: This century and the next, ed. R. Gotesky and E. Laszko, 39-64. New York: Gordon \& Breach.
Universal Declaration of Human Rights. 1948. http://www. un.org/en/documents/udhr/ (accessed October 10, 2009).

Warren, M.A. 1973. On the moral and legal status of abortion. The Monist 57(1): 43-61. Reprinted in Thomas A. Mappes and Jane S. Zembaty. 1991. Biomedical ethics (3rd Ed); New York: McGraw-Hill.

Wasserman, D., J. Bickenbach, and R. Wachbroit (eds.). 2005. Quality of life and human difference. New York: Cambridge University Press.

Wicks, E., M. Wyldes, and M. Kilby. 2004. Late termination of pregnancy for fetal abnormality: Medical and legal perspectives. Medical Law Review 12: 285-305. 